\title{
Efficiency and Effectiveness Thermal Analysis of the Shell and Helical Coil Tube Heat Exchanger Used in an Aqueous Solution of Ammonium Nitrate Solubility (ANSOL) with $20 \% \mathrm{H}_{2} \mathrm{O}$ and $80 \% A N$
}

\author{
Élcio Nogueira \\ Department of Mechanics and Energy (DEM), State University of Rio de Janeiro (UERJ), Resende, Brazil \\ Email: elcionogueira@hotmail.com
}

How to cite this paper: Nogueira, É. (2021) Efficiency and Effectiveness Thermal Analysis of the Shell and Helical Coil Tube Heat Exchanger Used in an Aqueous Solution of Ammonium Nitrate Solubility (ANSOL) with $20 \% \mathrm{H}_{2} \mathrm{O}$ and $80 \% A N$. Journal of Materials Science and Chemical Engineering, 9, 24-45.

https://doi.org/10.4236/msce.2021.96003

Received: April 10, 2021

Accepted: June 26, 2021

Published: June 29, 2021

Copyright $\odot 2021$ by author(s) and Scientific Research Publishing Inc. This work is licensed under the Creative Commons Attribution International License (CC BY 4.0).

http://creativecommons.org/licenses/by/4.0/

\begin{abstract}
The case study is about obtaining the flow rate and saturation temperature of steam that makes it possible to heat a solution of water and ammonia nitrate $(A N S O L)$ in a shell and helical coil tube heat exchanger, within a time interval, without that the crystallization of the $A N S O L$ solution occurs. The desired production per batch of the solution is $5750 \mathrm{~kg}$ in 80 minutes. The analysis uses the concepts of efficiency and effectiveness to determine the heat transfer rate and temperature profiles that satisfy the imposed condition within a certain degree of safety and with the lowest possible cost in steam generation. Intermediate quantities necessary to reach the objective are the Reynolds number, Nusselt number, and global heat transfer coefficient for the shell and helical coil tube heat exchanger. Initially, the water is heated for a specified period and, subsequently, the ammonium nitrate is added to a given flow in a fixed mass flow rate.
\end{abstract}

\section{Keywords}

Thermal Efficiency, Thermal Effectiveness, Shell and Helical Coil Tube, Heat Exchanger, Ammonium Nitrate

\section{Introduction}

The work's objective is to determine the heat transfer rate and temperature profiles necessary to heat a water and ammonium nitrate solution in a shell and helical coil tube heat exchanger without the solution's crystallization. 
It is about applying the efficiency and effectiveness method to determine the shell and helical coil tube heat exchanger thermal performance. The method of efficiency and effectiveness can be developed from the pioneering works of Adrian Bejan [1], during the 70s and 80s, related to the minimization of entropy in mechanical systems. In the late 1990s and early 2000 decade, Ahmad Fakheri [2] developed and applied the theory of efficiency and effectiveness to problems related to heat exchangers and viscous dissipation in different flows. Despite the simplicity of the model developed by Ahmad Fakheri, the Effectiveness Model ( $\varepsilon$-NUT) is still the most used for the thermal performance of heat exchangers. Élcio Nogueira [3] [4] has applied the efficiency and effectiveness method and has obtained promising results. These results are why the efficiency and effectiveness method is used in a relatively complex and without similar problem in the open literature in this work.

In the following paragraphs, a review of the literature related to the following topics is presented: solution methods for determining the thermal performance of heat exchangers, applications related to shell and helical coil tube heat exchangers, and the properties of ammonium nitrate $(A N)$.

Adrian Bejan [1] analyzes the thermodynamic irreversibility in mechanical and thermal devices based on minimizing entropy generation. The study focuses on the mechanisms responsible for the generation of heat entropy. It analyzes, among others, applications related to the areas of heat exchangers and thermal energy storage. The article presents a comprehensive review of works related to heat and mass transfer. The fundamental idea presented in the review carried out is that if a component's irreversibility is minimized, the reduction impacts the entire system.

Ahmad Fakheri [2] presents a solution for defining thermal efficiency for heat exchangers based on the works done by Adrian Bejan. It is shown that for each actual heat exchanger, there is an ideal counterflow heat exchanger associated with it. The ideal heat exchanger transfers the maximum amount of heat and generates a minimum amount of entropy, making it the most efficient. The heat exchanger's efficiency is equal to the actual heat transfer ratio about optimal heat transfer. The expressions of efficiency for a heat exchanger, presented by Ahamad, are similar to a fin's efficiency, with a single non-dimensional parameter defined by Fa. Ahmad Fakheri says that the concept of efficiency based on thermodynamics' second law provides a new perspective for analyzing heat exchangers. The algebraic form for determining efficiency depends on a single dimensionless parameter and eliminates the need for complex graphs or equations.

Élcio Nogueira [3] [4] [5] uses the concepts of efficiency and effectiveness to analyze problems related to heat exchangers. The first of the works [3] analyze the influence of the number of passes in a shell and tube condenser heat exchanger. Water-based nanofluid, with a fraction of aluminum oxide $\left(\mathrm{Al}_{2} \mathrm{O}_{3}\right)$ nanoparticles, circulates in the tubes. The parameters used to analyze the thermal performance of the heat exchanger are efficiency and effectiveness. The second 
work [4] aims to determine the best configuration for a shell and tube heat exchanger for water cooling, with volumetric fractions of copper oxide $(\mathrm{CuO})$ considered a parameter. The concepts of efficiency, effectiveness, and irreversibility determine the heat exchanger's thermal performance. The effectiveness method ( $\varepsilon$-NTU) [5] is applied in a radiator with multi-louvered flat-tube fins, with nanofluid as the working fluid. The nanofluid is composed of a suspension of silver nanoparticles in ethylene glycol. It has been shown that it is possible, using nanofluid, to reduce costs and storage space of the refrigerant.

Ashkan Alimoradi [6] performs calculations of heat transfer and entropy generation in forced convection in shell and helical tube heat exchangers. He analyzes the effect of the exchanger's geometric parameters such as tube diameter, coil diameter, shell diameter, coil height, shell height, and pitch on the heat transfer rate and entropy generation. Obtain critical values for the parameters so that the heat transfer coefficient can be maximized, and the entropy generation rate minimized. The importance of dimensionless geometrical parameters, which are desired in the design process, was demonstrated.

T. Srinivas, A. Venu Vinod [7] present studies on an agitated shell and helical coil heat exchanger using $\mathrm{CuO}$ /water nanofluid. Experiments have been carried out at various $\mathrm{CuO}$ nanoparticle concentrations in water, stirrer speeds, and shell-side fluid temperatures. Water has been used as the coil-side fluid at different values of the Dean number. Enhancement in heat transfer has been reported in terms of heat transfer rate. They concluded that the nanofluid has more effect on heat transfer compared to stirrer speed and shell-side temperature.

Ashkan Alimoradi and Farzad Veysi [8] investigate heat transfer in shell and helical tube heat exchangers. Numerical and experimental methods were used to examine the effect of the properties of fluids and geometric parameters in the Nusselt number. The thermal conductivity was considered dependent on the temperature in the numerical analysis. Two correlations were developed to predict Nusselt numbers on the side of the shell and the Coil side. The research covered a wide range of Reynolds and Prandtl numbers. There was good agreement with the experimental data.

M. R. Salimpour [9] investigated experimentally the heat transfer coefficients of shell and helically coiled tube heat exchangers with different coil pitches. Correlations were proposed for shell-side and tube-side, and the calculated heat transfer coefficients were compared to the existing correlations, and a reasonable agreement was observed.

Yamini Y. Pawar et al. [10] experimentally investigate the effect of different coils' geometric shapes on convection heat transfer in coil tube heat exchangers, helical, conical, and spiral types. The analysis shows that the convective heat transfer rate of the helical coil tube heat exchanger is 9.54\% higher than the other two geometries. Also, the helical coil heat exchanger is more efficient. The results demonstrate agreement between experimental values and values obtained 
using a computational tool (CFD).

R. Smusz [11] presents a study of heat transfer for the finned tube coil heat exchanger. A double-wall heat exchanger coil, located at the bottom head of the tank, is filled by freon. Correlations for heat transfer coefficients in curved tubes were applied. Analytical calculations and experimental studies of heat transfer characteristics for coil heat exchangers were performed.

Juanping Wang et al. [12] use a numerical method to analyze the effect of the mass flow rate on the loss of exergy in a finned helical coil tube heat exchanger. Hot water flows on the Coil side with a temperature of $70^{\circ} \mathrm{C}$ and speeds equal to $1 \mathrm{~m} / \mathrm{s}$, while cold, dry air with a temperature of $10^{\circ} \mathrm{C}$ flows through the hull with speeds equal to $1 \mathrm{~m} / \mathrm{s}$ and $4 \mathrm{~m} / \mathrm{s}$. The Nusselt number on the shell side and the friction factor on the coil side are compared with the experimental correlations. It was found that the loss of exergy is equal to $23.4 \%$ of the heat transfer rate.

P. J. Fule et al. [13] present a heat transfer enhancement study using water-based $\mathrm{CuO}$ nanofluids in a helical coil heat exchanger. They investigated the heat transfer coefficient and Nusselt number and it has been found that the increase in the loading of $\mathrm{CuO}$ nanoparticles shows a significant enhancement in the heat transfer coefficient, between $37.3 \%$ and $77.7 \%$.

Abhishek Nilay et al. [14] present a simulation of a helically coiled heat exchanger. The diameter coil, heat transfer rate, heat transfer coefficient, and Nusselt number have been analyzed. It has been found out that temperature drop decreases with a decrease in the coil diameter and an increase in mass flow rate, whereas the heat transfer rate increases with an increase in coil diameter and mass flow rate.

M. R. Salem et al. [15] present an experimental investigation of the heat transfer in horizontal shell and coil heat exchangers and the friction factor for fully developed flow. The tests were performed for $\mathrm{Al}_{2} \mathrm{O}_{3}$ with an average size of $40 \mathrm{~nm}$ and particle volume concentration from $0 \%$ to $2 \%$. Results illustrated that NUT is higher than those of pure water at the same flow condition. Results showed that NUT increase by increasing the coil curvature ratio. Also, correlations for NUT are obtained.

Amitkumar et al. [16] claim helical coil heat exchangers can provide a high heat transfer coefficient. They evaluate the thermal performance of a counterflow helical coil heat exchanger. They consider cold water flow, hot water flow, temperature, efficiency, and global heat transfer coefficient.

Hamid Abdi et al. [17] perform a comparative numerical study and analyze the heat transfer performance in the laminar regime of nanofluid composed of water and aluminum oxide $\left(\mathrm{Al}_{2} \mathrm{O}_{3}\right)$ in spiral and helical tubes. They use finite elements as a tool for solving the equations that govern fluid flow. They determine which tube in helical configuration allows more significant heat transfer compared to straight tubes. Although the helical tube has better heat transfer performance, the pressure drop is more significant.

Ammonium nitrate $(A N)$ is widely used in fertilizer industry. However, $A N$ is 
associated with explosives, which can detonate under certain conditions. Zhe Han [18] presents a dissertation to understand the fundamental causes associated with $A N$ explosion and make storage safer by studying thermal stability. The research developed focuses on the decomposition of $A N$ depending on the condition, including additives and heating rate. Also, the paper discusses the role of water as a chemical, interfering physically and chemically in fire scenarios related to $A N$. The study demonstrated that $A N$ is stable up to approximately $200^{\circ} \mathrm{C}$. The work reflects the complexity and care needed to make $A N$ more secure. Also, the study carried out can serve as a model for several other reactive chemicals.

Spacing and type styles are built-in; examples of the type styles are provided throughout this document and are identified in italic type, within parentheses, following the example. Some components, such as multi-leveled equations, graphics, and tables are not prescribed, although the various table text styles are provided. The formatter will need to create these components, incorporating the applicable criteria that follow.

\section{Methodology}

The desired production per batch of the solution $(A N S O L)$ is $5750 \mathrm{~kg}$ in $80 \mathrm{mi}$ nutes. For five minutes, $1150 \mathrm{~kg}$ of water enters the shell at a temperature of $30^{\circ} \mathrm{C}$. The mass of water is heated for ten minutes. After heating the water, 4600 $\mathrm{kg}$ of nitrate is inserted at a mass flow rate equal to $1.394 \mathrm{~kg} / \mathrm{s}$ for fifty-five minutes. The maximum flow rate of steam available to heat the solution is equal to $800 \mathrm{~kg} / \mathrm{h}$, and the steam's maximum saturation pressure is equal $361.30 \mathrm{kPa}$ $\left(140^{\circ} \mathrm{C}\right)$. The heat exchanger consists of a shell with an internal diameter of 2.2 meters and a height of 1.932 meters. There are two rows of coils with an internal diameter of $54.79 \mathrm{~mm}$ and a height of 1.6 meters, with ten volutes. Each volute's length is 5.65 meters, and the total length for heat exchange is 113 meters. There are two agitators with a $53 \mathrm{~mm}$ diameter propeller each and a stirring speed of $130 \mathrm{rpm}$. The shell is covered with thermal Rockwool insulation, and the loss of heat to the environment is considered insignificant.

In this sub-item, we detail the mathematical and physical formulation to analyze the heat exchanger's configuration.

The problem solution begins with the stipulation of a steam fraction, a given steam saturation temperature, and one of the steam's possible mass flow rates.

The water mass $M_{\mathrm{H}_{2} \mathrm{O}}$ enters the tank for the first five minutes at a temperature of $20^{\circ} \mathrm{C}$. During these five minutes, there is no heating of the water. After entering the entire mass of water, the process of heating the compound begins. During the next ten minutes, the water heats up, and its final temperature in this time interval depends on the saturation temperature $\left(T_{s a t V}\right)$, the steam fraction considered $(X)$, and the fraction of the coil area $\left(A_{\text {Iransf }}\right)$ occupied by the water in the shell.

$$
M_{\text {ANbatch }}=4600 \mathrm{~kg}
$$




$$
\begin{gathered}
M_{\mathrm{H}_{2} \mathrm{O}}=1150 \mathrm{~kg} \\
M_{\text {Totbach }}=M_{\text {ANbatch }}+M_{\mathrm{H}_{2} \mathrm{O}}=5750 \mathrm{~kg} \\
D d i=0.05479 \mathrm{~m} ; \text { Schedule } 10(54.79 \mathrm{~mm}) \\
\text { Ddo }=0.06030 \mathrm{~m}
\end{gathered}
$$

Ddi and Ddo are the inner and outer diameters of the Coil, respectively.

Was considered variations in the steam fraction $(X)$, saturation temperature $\left(T_{\text {SatV }}\right)$, and mass flow rate of the steam $\left(\dot{m}_{V}\right)$. The steam fraction suffered variations from 0.0 to 1.0. The saturation temperature was considered equal to $100^{\circ} \mathrm{C}, 120^{\circ} \mathrm{C}$, and $130^{\circ} \mathrm{C}$ for analysis. The steam's mass flow rate varies between the two extremes $(300 \mathrm{~kg} / \mathrm{hr}$ and $800 \mathrm{~kg} / \mathrm{hr})$.

Figure 1 presents an overview of the shell and arrangement of the rows of coils with agitators. Figure 2 shows a schematic view of the dimensions of one helical coil tube heat exchanger without agitators.

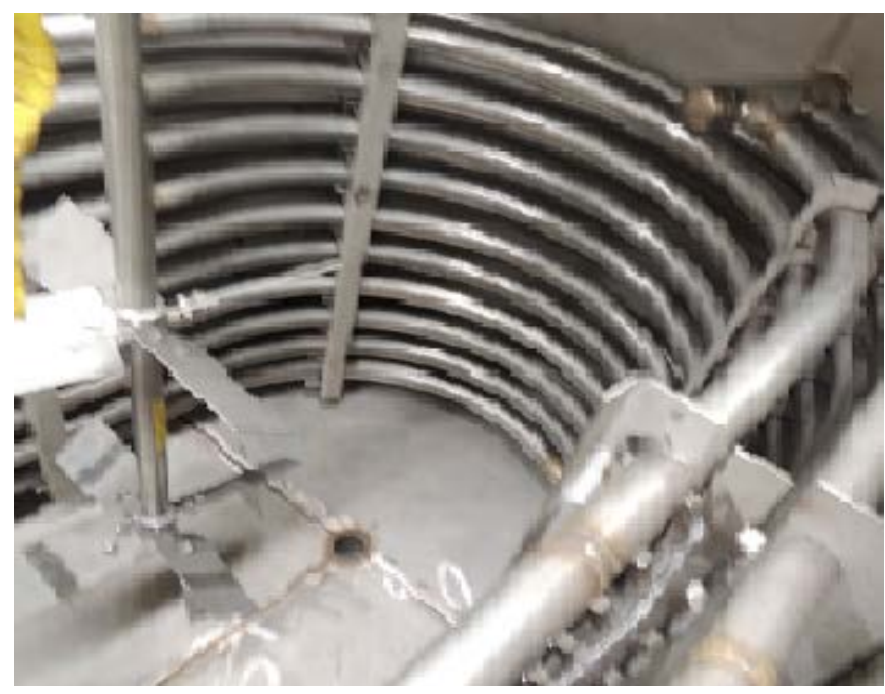

Figure 1. Overview of the shell, coils, and agitators.

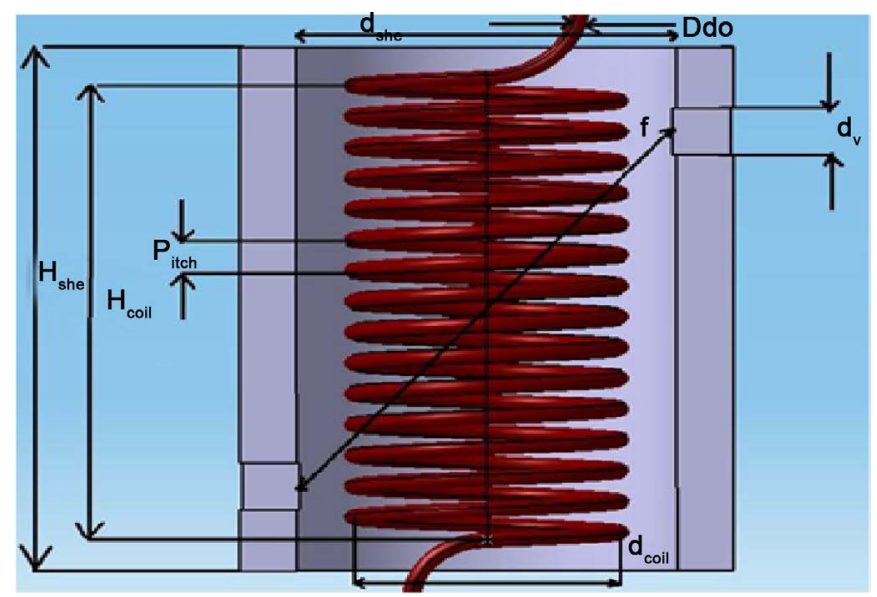

Figure 2. Schematic view of the dimensions of the one helical coil tube heat exchanger Adapted from [6]. 
During the heating of the water, do it:

$$
M_{\text {ANSOL }}=M_{\mathrm{H}_{2} \mathrm{O}}
$$

After the heating of the water, do it:

$$
\begin{gathered}
\Phi_{\text {ANRate }}=M_{\text {ANbatch }} / 3300 \mathrm{~kg} / \mathrm{s} \\
M_{\text {ANSOL }}=\Phi_{\text {ANRate }} * t+M_{\mathrm{H}_{2} \mathrm{O}} \text { after heat water } \\
\varnothing_{\text {AN }}=\left(\Phi_{\text {ANRate }} * t\right) / M_{\text {ANBatch }}
\end{gathered}
$$

$\varnothing_{A N}$ is the fraction $\mathrm{f}$ ANintime; $t$ is the time in seconds.

$$
R_{f}=0.00018\left(\mathrm{~m}^{2} \cdot{ }^{\circ} \mathrm{C}\right) / \mathrm{W}
$$

$R_{f}$ is he fouling factor.

$$
L A=0.53 \mathrm{~m}
$$

$L A$ is the agitator diameter.

$$
N_{\text {Rev }}=130 \mathrm{rpm}
$$

$N_{R e v}$ is the maximum value for agitator.

$$
\begin{aligned}
& N_{\text {Exp }}=7013 \\
& A 2=0.5414 \\
& M M=0.1415
\end{aligned}
$$

$N_{\text {Exp }}, A 2$ and $M M$ are experimental parameters associated with the calculation of Reynolds and Nusselt numbers for $A N S O L$.

$$
\mathrm{Del}_{\text {Steel }}=\mathrm{Ddo}-\mathrm{Ddi}
$$

$\mathrm{Del}_{\text {Steel }}$ is the steel tube thickness.

$$
k_{\text {Steel }}=50 \mathrm{~W} /\left(\mathrm{m} \cdot{ }^{\circ} \mathrm{C}\right)
$$

$k_{\text {Steel }}$ is the thermal conductivity of steel.

$$
\begin{gathered}
P_{\text {SatV }}=-0.02236703337+0.002632754283 * T_{\text {Sat } V} \\
-5.609709888 * 10^{-5} * T_{\text {SatV }}^{2}+4.084316356 * 10^{-7} * T_{\text {Sat } V}^{3} \\
P_{\text {SatV }}=P_{\text {SatV }} * 10^{6}
\end{gathered}
$$

$P_{\text {SatV }}$ is the vapor pressure for a given vapor saturation temperature $T_{\text {SatV }}$.

$$
d_{\text {She }}=2.2 \mathrm{~m}
$$

$d_{\text {She }}$ is the shell radius.

$$
A_{\text {She }}=\pi * d_{\text {she }}^{2} / 4 \mathrm{~m}^{2}
$$

$A_{\text {She }}$ is the straight section area of the shell.

$$
H_{\text {She }}=1.932 \mathrm{~m}
$$

$H_{\text {She }}$ is the shell height.

$$
V_{\text {She }}=A_{\text {She }} * H_{\text {She }} \mathrm{m}^{3}
$$

$V_{\text {She }}$ is the shell volume.

$$
H_{\text {Coil }}=1.5502 \mathrm{~m}
$$


$H_{\text {Coil }}$ is the Coil height.

$$
V_{\text {Coil }}=A_{\text {She }} * H_{\text {coil }} \mathrm{m}^{3}
$$

$V_{\text {Coil }}$ is the volume occupied by Coil.

$$
A_{\text {Coil }}=\left(\pi * D d i^{2}\right) / 4 \mathrm{~m}^{2}
$$

$A_{\text {Coil }}$ is the straight section area of the Coil.

$$
\begin{aligned}
& L_{\text {Volute }}=5.897 \mathrm{~m} \\
& D_{\text {Coil }}=L_{\text {Volute }} / \pi
\end{aligned}
$$

$D_{\text {Coil }}$ is the Coil diameter.

$$
\begin{gathered}
N_{\text {Volute }}=20 \\
L_{\text {TotCoil }}=N_{\text {Volute }} * L_{\text {Volute }} \mathrm{m} \\
A_{\text {Iroca }}=\pi * D d o * L_{\text {TotCoil }}
\end{gathered}
$$

$A_{\text {Iroca }}$ is the heat exchange area.

$$
\begin{aligned}
\text { Pitch } & =0.125 \mathrm{~m} ; \text { provided } \\
\gamma & =\operatorname{Pitch} /\left(\pi * D_{\text {Coil }}\right)
\end{aligned}
$$

$\gamma$ is the Pitch ratio.

$$
D_{\text {hShe }}=\left(D_{\text {Sheb }}^{2}-\pi D_{\text {Coil }} D d o^{2} \gamma^{-1}\right) /\left(D_{\text {Sheb }}+\pi D_{\text {Coil }} D d o \gamma^{-1}\right)
$$

$D_{h S h e}$ is the hydraulic shell diameter [9] [16].

$$
\text { Delta }=\text { Ddi } / D_{\text {Coil }}
$$

Delta is the Coil curvature radius.

$$
\begin{aligned}
\text { Visc }_{V I}= & 0.001786336413-5.817305783 * 10^{-5} * T_{\text {Sat } V} \\
+ & 1.234757763 * 10^{-6} * T_{\text {Sat }}^{2}-1.714084113 * 10^{-8} * T_{\text {Sat } V}^{3} \\
+ & 1.515721805 * 10^{-10} * T_{\text {Sat }}^{4}-8.351845995 * 10^{-13} * T_{\text {Sat }}^{5} \\
+ & 2.759065389 * 10^{-15} * T_{\text {SatV }}^{6}-4.982793053 * 10^{-18} * T_{\text {Sat } V}^{7} \\
+ & 3.773340497 * 10^{-21} * T_{\text {Sat } V}^{8} \\
\text { Visc }_{V V}= & 9.140400757 * 10^{-6}+2.939469488 * 10^{-8} * T_{\text {Sat } V} \\
& +1.750995661 * 10^{-11} * T_{\text {Sat }}^{2} \\
& \mu_{V}=\operatorname{Visc}_{V V} * X+(1 . d 0-X) * \operatorname{Visc}_{V l}
\end{aligned}
$$

$\mu_{V}$ is the dynamic vapor viscosity.

$$
R e_{V}=\left(4 \dot{m}_{V}\right) /\left(\pi D d i \mu_{V}\right)
$$

$R e_{V}$ is the Reynolds number for steam.

$$
\begin{gathered}
P r_{V l}=13.54579655-0.492833509 * T_{\text {SatV }}+0.01090463685 * T_{\text {Sat } V}^{2} \\
-0.0001522784983 * T_{\text {SatV }}^{3}+1.337432842 * 10^{-6} * T_{\text {SatV }}^{4} \\
-7.29382169 * 10^{-9} * T_{\text {SatV }}^{5}+2.384346061 * 10^{-11} * T_{\text {Sat }}^{6} \\
-4.264567877 * 10^{-14} * T_{\text {SatV }}^{7}+3.201983283 * 10^{-17} * T_{\text {SatV }}^{8} \\
\operatorname{Pr}_{V V}=1.0
\end{gathered}
$$




$$
P r_{V}=P r_{V v} * X+(1 . d 0-X) * P r_{V l}
$$

$\operatorname{Pr}_{V}$ is the Prandtl number for steam.

$$
\begin{gathered}
\operatorname{Dean}_{V}=\left(\left(\operatorname{Re}_{V}\left(\operatorname{Ddo} / D_{\text {Coil }}\right)\right)^{2.5}\right)^{1 / 6} \\
N u_{V}=0.023\left(1+0.061 / \text { Dean }_{V}\right)\left(\text { Ddo }_{D_{\text {Coil }}}\right)^{1 / 2} \operatorname{Re}_{V}^{0.833} \operatorname{Pr}_{V}^{0.4}
\end{gathered}
$$

$N u_{V}$ is the Nusselt number for the steam [19].

$$
\begin{gathered}
k_{V l}=0.5585441658+0.002336001518 * T_{\text {Sat }}-1.466562794 * 10^{-5} * T_{\text {SatV }}^{2} \\
+3.890051788 * 10^{-8} * T_{\text {Sat } V}^{3}-5.454053006 * 10^{-11} * T_{\text {SatV }}^{4} \\
K_{V v}=0.01727949556+3.076143072 * 10^{-5} * T_{\text {Sat } V} \\
+7.089894385 * 10^{-7} * T_{\text {SatV }}^{2}-2.908678135 * 10^{-9} * T_{\text {Sat }}^{3} \\
+7.06665225 * 10^{-12} * T_{\text {Sat }}^{4} \\
k_{V}=k_{V V} * X+(1 . d 0-X) * k_{V l} \\
h_{V C}=\left(N u_{V} k_{V}\right) / D d i
\end{gathered}
$$

$h_{V C}$ is the steam convection heat transfer coefficient.

$$
\begin{gathered}
k_{\text {Water }}=k_{V l} \\
\mu_{\text {Water }}=V i s C_{V l} \\
P r_{\text {Water }}=P r_{V l} ; \text { Prandtl number for water } \\
C p_{V l}=6346.4902-51.59537622 * T_{\text {SatV }}+0.4513794949 * T_{\text {SatV }}^{2} \\
-0.001686126745 * T_{\text {SatV }}^{3}+2.442135123 * 10^{-6} * T_{\text {SatV }}^{4} \\
C p_{V v}=5510.77695-90.07137297 * T_{\text {SatV }}+0.8293046313^{-} * T_{\text {SatV }}^{2} \\
-0.003196361184 * T_{\text {SatV }}^{3}+4.833313924 * 10^{-6} * T_{\text {SatV }}^{4} \\
C p_{V}=C p_{V v} * X+(1 . d 0-X) * C p_{V l}
\end{gathered}
$$

$C p_{V}$ is the specific heat of the steam.

$$
\begin{gathered}
C p_{\text {Water }}=C p_{V l} \\
h_{V l}=6.904741451+3.921624179 * T_{\text {SatV }}+0.00165124788 * T_{\text {Sat }}^{2} \\
h_{V V}=2501.216798+1.793800226 * T_{\text {Sat } V}+0.0007148096104 * T_{\text {Sat }}^{2} \\
-1.203406572 * 10^{-5} * T_{\text {SatV }}^{3} \\
h_{V}=h_{V V} * X+(1 . d 0-X) * h_{V l}
\end{gathered}
$$

$h_{V}$ is the enthalpy of steam.

$$
\begin{gathered}
h_{l V}=h_{V}-h_{V l} \\
\rho_{A N}=(1322+1353+1428) / 3=1367 \mathrm{~kg} / \mathrm{m}^{3} \\
\rho_{\text {Water }}=1002.228973-0.1722194782 * T_{\text {SatV }}-0.002608298301 * T_{\text {Sat } V}^{2} \\
\rho_{\text {ANSOL }}=\rho_{A N} * \varnothing_{A N}+\left(1 . d 0-\varnothing_{A N}\right) * \rho_{\text {Water }} \\
\mu_{A N}=\left(2.24 * 10^{-3}+1.98 * 10^{-3}\right) / 2
\end{gathered}
$$


$\mu_{A N}$ is the ammonium nitrate viscosity.

$$
C p_{\text {AN }}=2130 \mathrm{~J} /\left(\mathrm{kg} \cdot{ }^{\circ} \mathrm{C}\right)
$$

$C p_{A N}$ is the ammonium nitrate specific heat.

$$
\mu_{\text {ANSOL }}=\mu_{A N} * \varnothing_{A N}+\left(1 . d 0-\varnothing_{A N}\right) * \mu_{\text {Water }}
$$

$\mu_{\text {ANSOL }}$ is the solution viscosity.

$$
C p_{\text {ANSOL }}=C p_{A N} * \varnothing_{A N}+\left(1 . d 0-\varnothing_{A N}\right) * C p_{\text {Water }}
$$

$C p_{\text {ANSOL }}$ is the solution specific heat.

$$
\begin{gathered}
k_{A N}=0.4 \mathrm{~W} /(\mathrm{m} \cdot \mathrm{K}) ; \text { provided } \\
k_{\text {ANSOL }}=K_{A N} * \varnothing_{A N}+\left(1 . d 0-\varnothing_{A N}\right) * K_{\text {Water }} \\
\alpha_{A N S O L}=k_{N S O L} /\left(\rho_{A N S O L} C p_{A N S O L}\right) \\
v_{A N S O L}=\mu_{A N S O L} / \rho_{A N S O L} \\
\operatorname{Pr}_{A N S O L}=v_{A N S O L} / \alpha_{A N S O L}
\end{gathered}
$$

$\operatorname{Pr}_{\text {ANSOL }}$ is the Prandtl number of the $A N S O L$.

$$
R e_{\text {ANSOL }}=L A^{2}\left(N_{\text {Rev }} / N_{E x p}\right)\left(\rho_{\text {ANSOL }} / \mu_{\text {ANSOL }}\right)
$$

$R e_{\text {ANSOL }}$ is the Reynolds number of the $A N S O L$ [20].

$$
N u_{\text {ANSOL }}=A 2 \operatorname{Re}_{\text {ANSOL }}^{2 / 3} \operatorname{Pr}_{\text {ANSOL }}^{1 / 3}\left(\mu_{\text {ANSOL }} / \mu_{\text {Water }}\right)^{M M}
$$

$N u_{\text {ANSOL }}$ is the Nusselt number of the $A N S O L$ [20].

$$
h_{\text {ANSOL }}=\left(N u_{\text {ANSOL }} k_{\text {ANSOL }}\right) / D_{h S h e}
$$

$h_{\text {ANSOL }}$ is the $A N S O L$ convection heat transfer coefficient.

$$
U o=1 /\left((D d o / D d i) / h_{\text {ANSOL }}+(D d o L n(D d o / D d i)) /\left(2 k_{\text {Steel }}\right)+1 / h_{V C}+R f\right)
$$

Uo is the global heat transfer coefficient.

$$
\begin{gathered}
V_{\text {ANSOL }}=M_{\text {ANSOL }} / \rho_{\text {ANSOL }} \\
F r_{\text {Vol }}=V_{\text {ANSOL }} / V_{\text {Coil }}
\end{gathered}
$$

$\mathrm{Fr}_{V o l}$ is the volume fraction of the $A N S O L$.

$$
C_{V}=\dot{m}_{V} * C p_{V}
$$

$C_{V}$ is the thermal capacity of the steam.

$$
C_{\text {ANSOL }}=\dot{m}_{\text {ANSOL }} * C p_{\text {ANSOL }}
$$

$C_{\text {ANSOL }}$ is the thermal capacity of the ANSOL.

$$
\begin{gathered}
C_{*}=C_{\text {Min }} / C_{\text {Max }} \\
A_{\text {Transf }}=A_{\text {Troca }} * F r_{\text {Vol }}
\end{gathered}
$$

$A_{\text {Transf }}$ is actual heat transfer area.

$$
\text { heat }_{\mathrm{AN}}=321000 * \Phi_{\text {ANRate }} \mathrm{J} / \mathrm{s}
$$

heat $_{\mathrm{AN}}$ is the dissolution energy of $A N$.

$$
N T U=\left(A_{\text {Transf }} U o\right) / C_{\text {Min }}
$$


$N T U$ is the number of thermal units associated with the $A N S O L$.

$$
\begin{gathered}
F a=(N T U / 2) \sqrt{1+C_{*}^{2}} \\
\eta_{T}=\operatorname{Tanh}(\mathrm{Fa}) / F a
\end{gathered}
$$

$\eta_{T}$ is the thermal efficiency associated with the heat exchange process [1,2].

$$
\varepsilon_{T}=1 /\left(1 /\left(\eta_{T} N T U\right)+1 /\left(1-C_{*}\right)\right)
$$

$\varepsilon_{T}$ is the thermal effectiveness associated with the heat exchange process $[1,2]$.

$$
\begin{gathered}
\dot{Q}_{\text {Actual }}=\left(\left(T_{\text {SatV }}-T_{0}\right) C_{\text {Min }}\right) /\left(1 /\left(\eta_{T} N T U\right)+\left(1+C_{\text {Ast }}\right) / 2\right) ; \text { for water } \\
\dot{Q}_{\text {Actual }}=\left(\left(T_{\text {SatV }}-T_{0}\right) C_{\text {Min }}\right) /\left(1 /\left(\eta_{T} N T U\right)+\left(1+C_{\text {Ast }}\right) / 2\right)-\text { heat }_{A N} ; \text { for AN }
\end{gathered}
$$

$\dot{Q}_{\text {Actual }}$ is the heat exchange energy per unit of time (J/s) [1,2].

$$
T_{\text {ANSOL }}=T_{0}+\left(\dot{Q}_{\text {Actual }} / C_{\text {ANSOL }}\right)
$$

After heating the water, do it:

$$
T_{0}=T_{\text {ANSOL }}
$$

$T_{\text {ANSOL }}$ is the temperature of the $A N S O L$ over time:

$$
t=4200 \text { second }
$$

To calculate the temperature over time, do it:

$$
\begin{gathered}
\Delta T 1=T_{\text {SatV }}-T_{0} \\
\Delta T 2=T_{\text {SatV }}-T_{\text {ANSOL }} \\
\Delta T_{L n}=(\Delta T 1-\Delta T 2) / \operatorname{Ln}(\Delta T 1 / \Delta T 2) \\
T_{\text {ANSOL }}=\left(A_{\text {Iransf }} U o \Delta T_{L n}\right) /\left(M_{\text {ANSOL }} C p_{\text {ANSOL }}\right) t+T_{0}
\end{gathered}
$$

Summary of the procedure used in the solution:

The heat exchange process starts after the water enters the shell (5 minutes). The water heats up for 10 minutes, with stipulated inputs for the following parameters: the steam fraction, the saturation temperature, the steam mass flow rate, and the water's mass flow rate. After heating the water, the $A N$ s mass fraction begins over time and the mixture's heating for 55 minutes and $T_{0}=T_{\text {ANSOL }}$ finds itself lagging in time.

\section{Results and Discussion}

Figure 3 shows the volume fraction occupied by the aqueous ammonium nitrate solution $(A N S O L)$ as a function of time. During the first ten minutes of heating the water, the volume fraction remains constant. The addition of ammonium nitrate occurs uniformly, with five bags of $920 \mathrm{~kg}$ every 10 minutes. With the addition of ammonium nitrate, at 15 minutes, there is a momentary expansion in volume fraction. From this moment on, there is a consistent growth in the volume fraction occupied by $A N S O L$. At approximately 65 minutes, the volume reaches the volume occupied by the Coil and then remains constant until the addition, at seventy minutes of ammonium nitrate. 


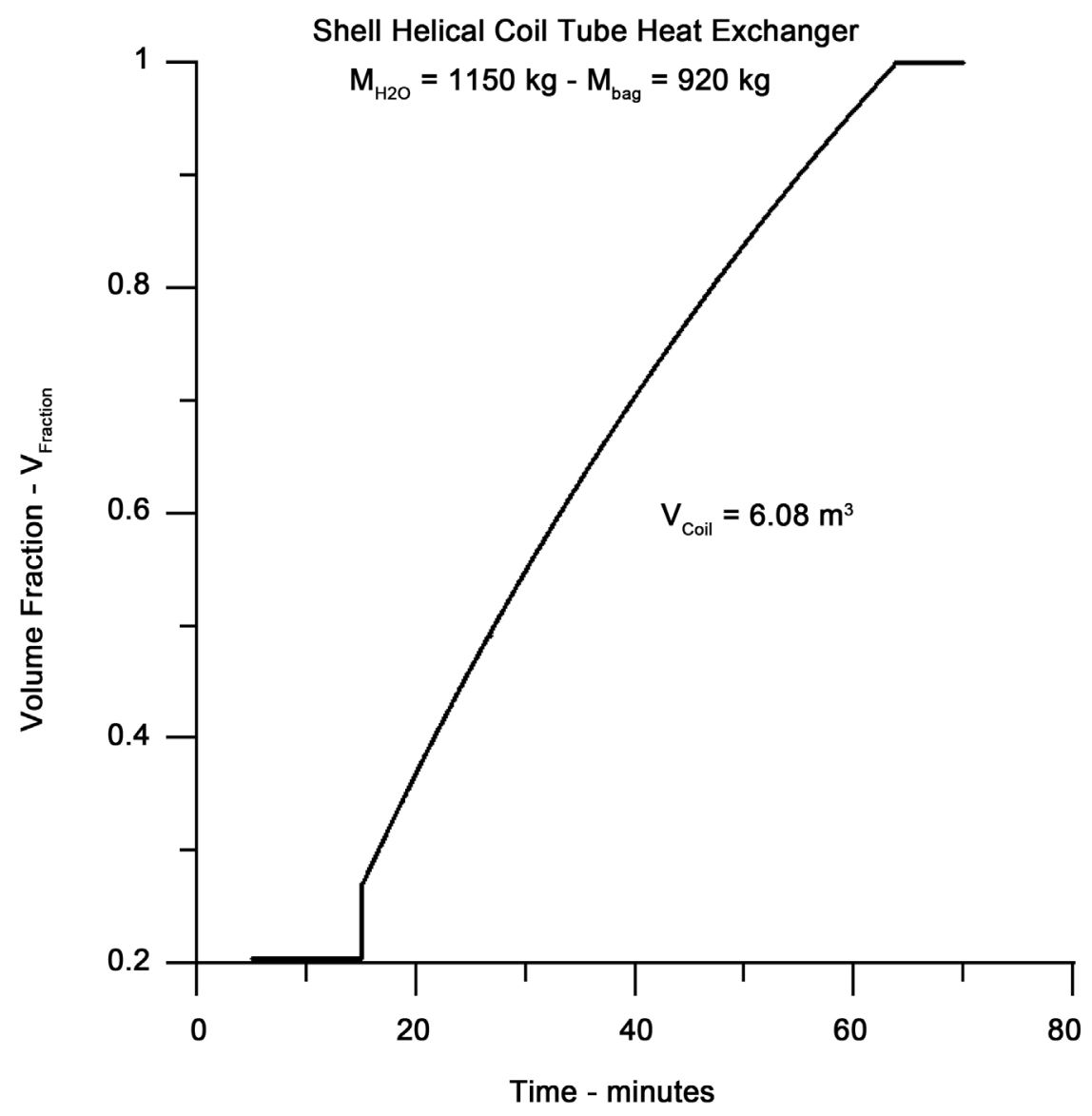

Figure 3. Volume occupied by $A N S O L$ versus time.

Figure 4 shows the heat transfer area as a function of time. The heat transfer area remains constant during the heating of the water. At 15 minutes, there is an expansion of the area occupied by the solution (ANSOL). Then there is a continuous growth in the heat exchange area, as ammonium nitrate is added. At 70 minutes, all available heat exchange area is occupied by ANSOL.

The number of Reynolds associated with the solution of water and ammonium nitrate is represented by Figure 5 . At the beginning of the addition ammonium nitrate, the Reynolds number is high due to the lower mass, close to 2.4 $10^{6}$. At the end of addition ammonium nitrate, with almost all the mass already inserted, the Reynolds number approaches $4.0 \times 10^{5}$.

The Prandtl number, with saturation temperature as a parameter, is represented by Figure 6 . The number of Prandtl decreases slightly with the increase in the saturation temperature at the beginning of ammonium nitrate addition due to greater thermal diffusivity. Over time, when the mass of ammonium nitrate is high, the number of Prandtl tends to approach 11 and is independent of the saturation temperature. In this last situation, mass transport diffusivity prevails about thermal diffusivity. The Nusselt number increases with time, and with the saturation temperature, due to the higher viscosity of $A N S O L$ about water (Figure 7). 


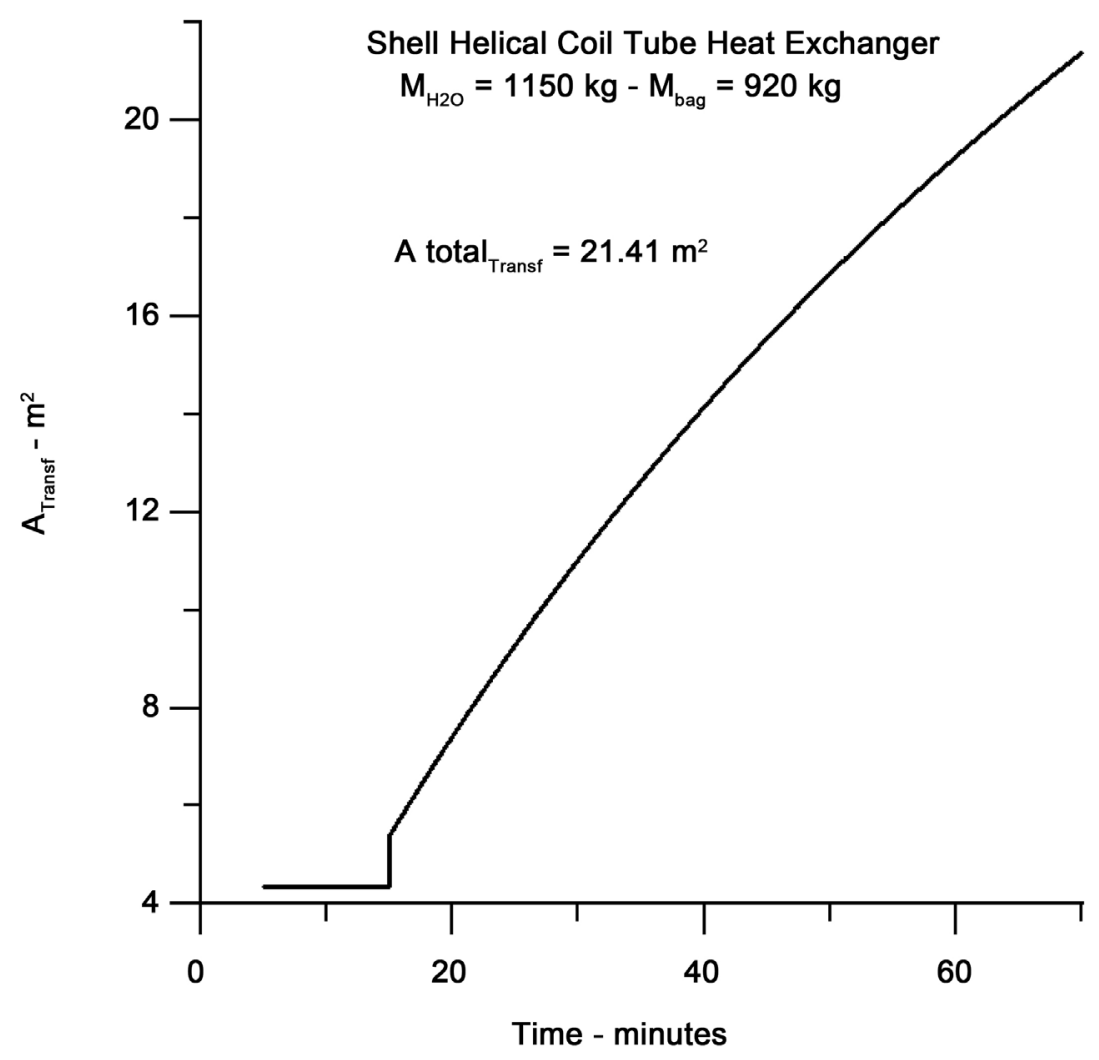

Figure 4. Heat transfer area versus time.

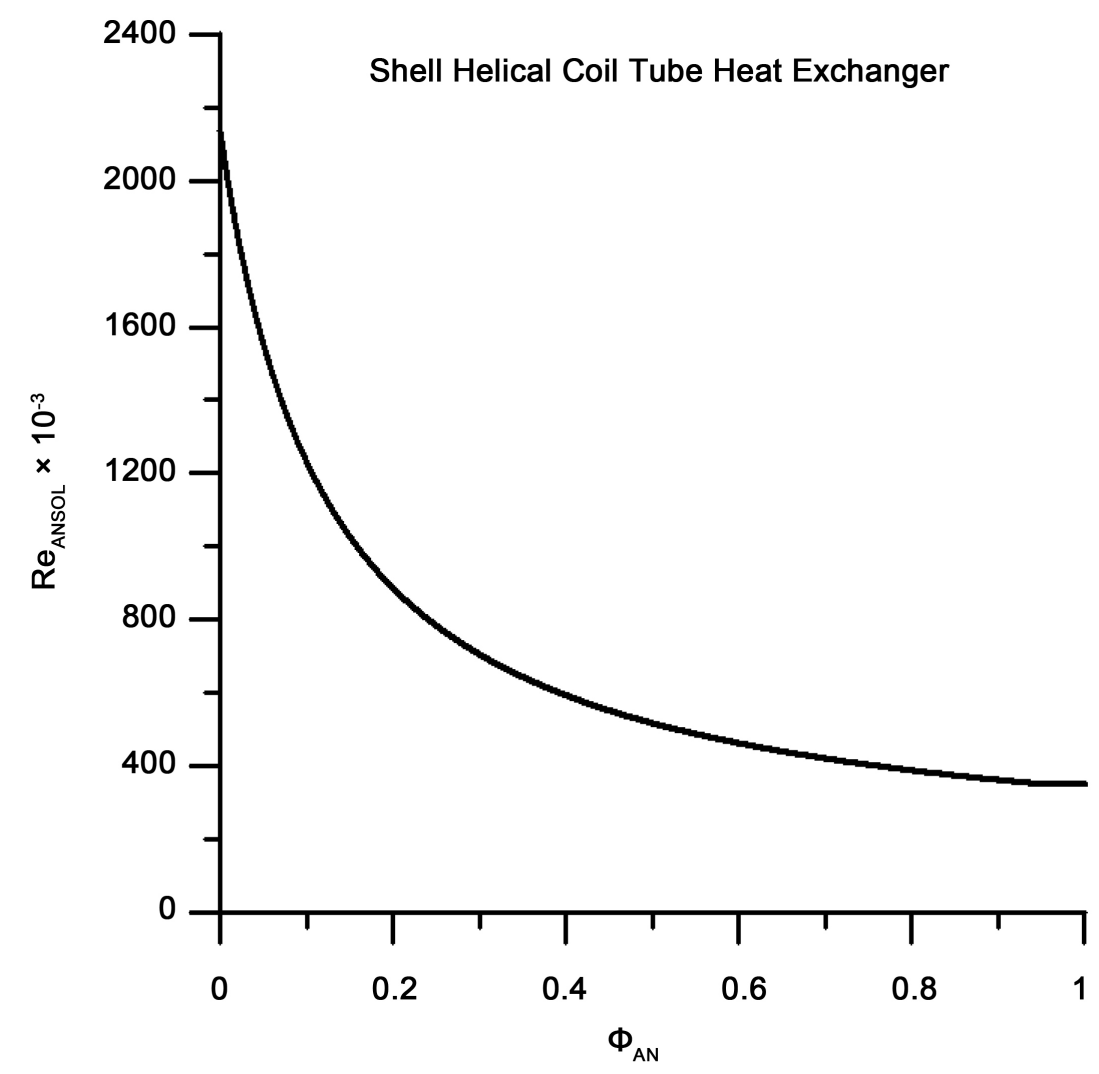

Figure 5. Reynolds number of the solution versus ammonium nitrate fraction. 


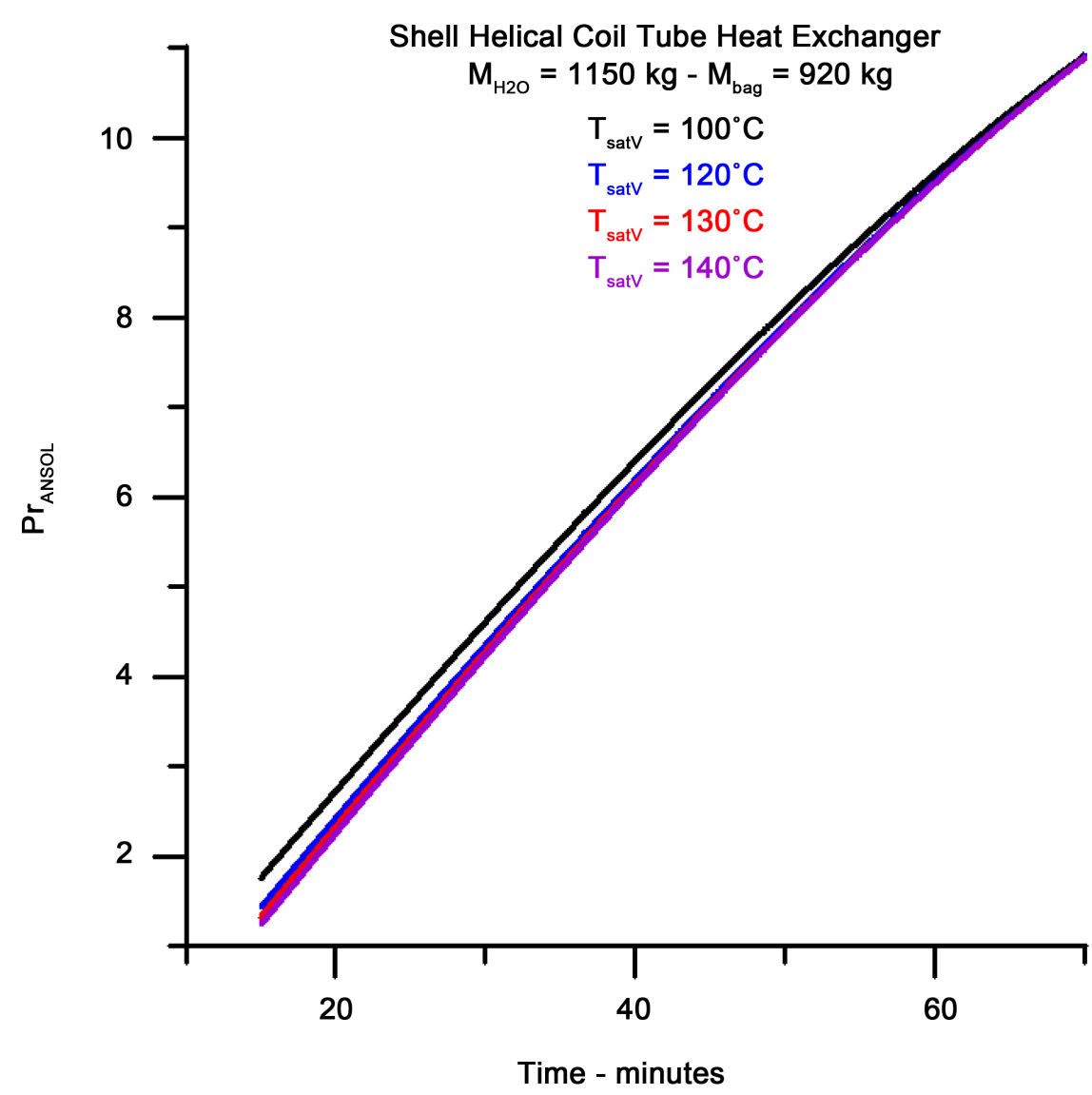

Figure 6. Prandtl number versus time with saturation temperature as a parameter.

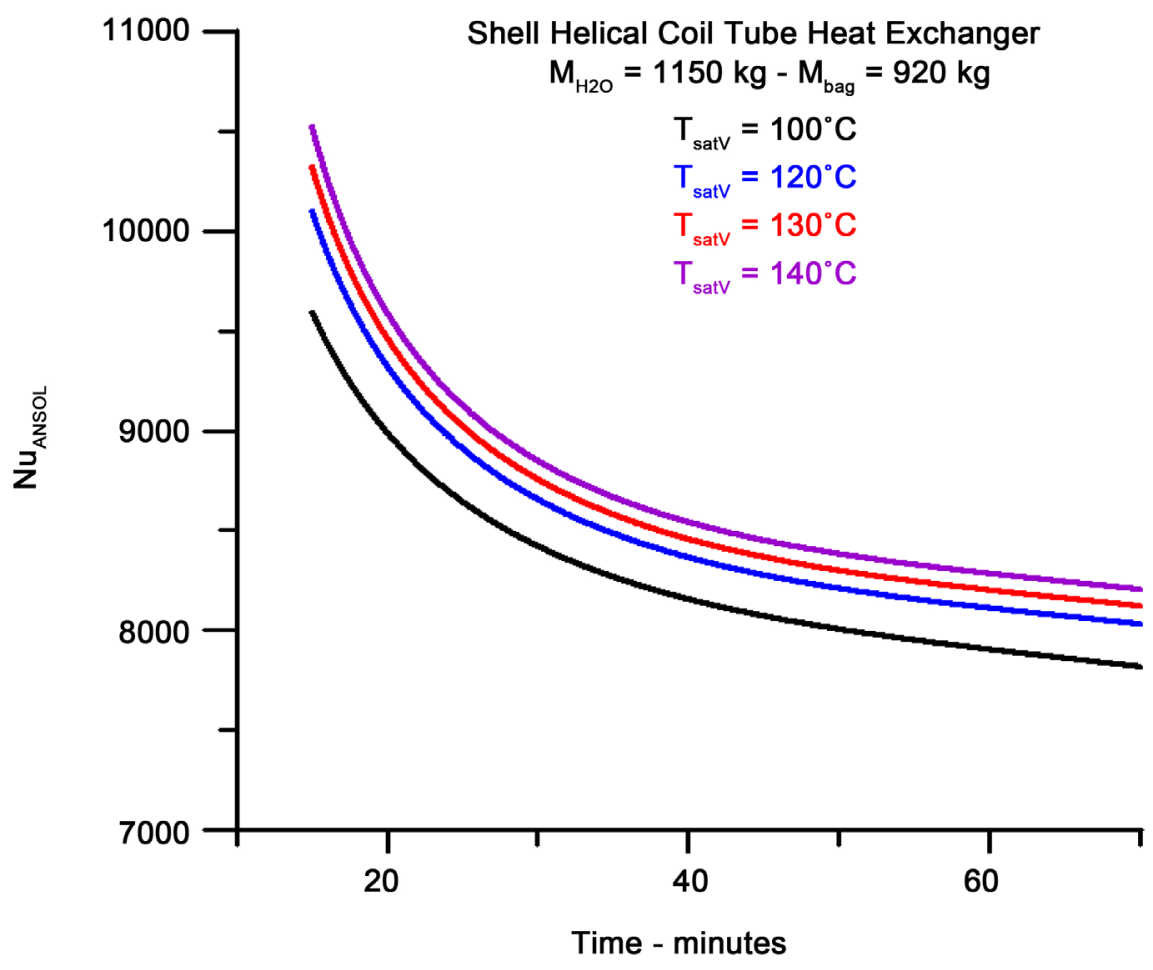

Figure 7. Nusselt number versus time with saturation temperature as a parameter. 
The global heat transfer coefficient, with the steam saturation temperature as a parameter, is represented by Figure 8 and Figure 9, with steam flow rates equal to $300 \mathrm{~kg} / \mathrm{hr}$ and $400 \mathrm{~kg} / \mathrm{hr}$, respectively, and steam fractions equal to 0.0 and 1.0. The overall heat transfer coefficient increases with steam's mass flow rate, with the saturation temperature, and with the decrease in the vapor fraction. The overriding factor in determining the overall heat transfer coefficient is the convection coefficient in steam. As steam has less thermal diffusivity than water, the overall heat transfer coefficient is higher for smaller steam fractions.

The thermal efficiency of the heating and mixing process of $A N S O L$ is shown through Figure 10 and Figure 11. The highest efficiency corresponds to the fraction of steam equal to 1.0 (dry saturated steam) and the lowest saturation temperature analyzed $\left(100^{\circ} \mathrm{C}\right)$. It should be noted that greater thermal efficiency means less energy exchange in the form of heat, or minor generation of entropy. The results obtained are in concordance with the global heat transfer coefficient values determined and presented through Figure 8 and Figure 9. There is a slight difference between the thermal efficiencies obtained for mass flow rates of steam equal to $300 \mathrm{~kg} / \mathrm{hr}$ and $400 \mathrm{~kg} / \mathrm{hr}$, with the highest value obtained for the latter flow rate, where energy in the form of heat is better used, as it is absorbed to heat a greater mass of $A N S O L$. This higher value is justified because

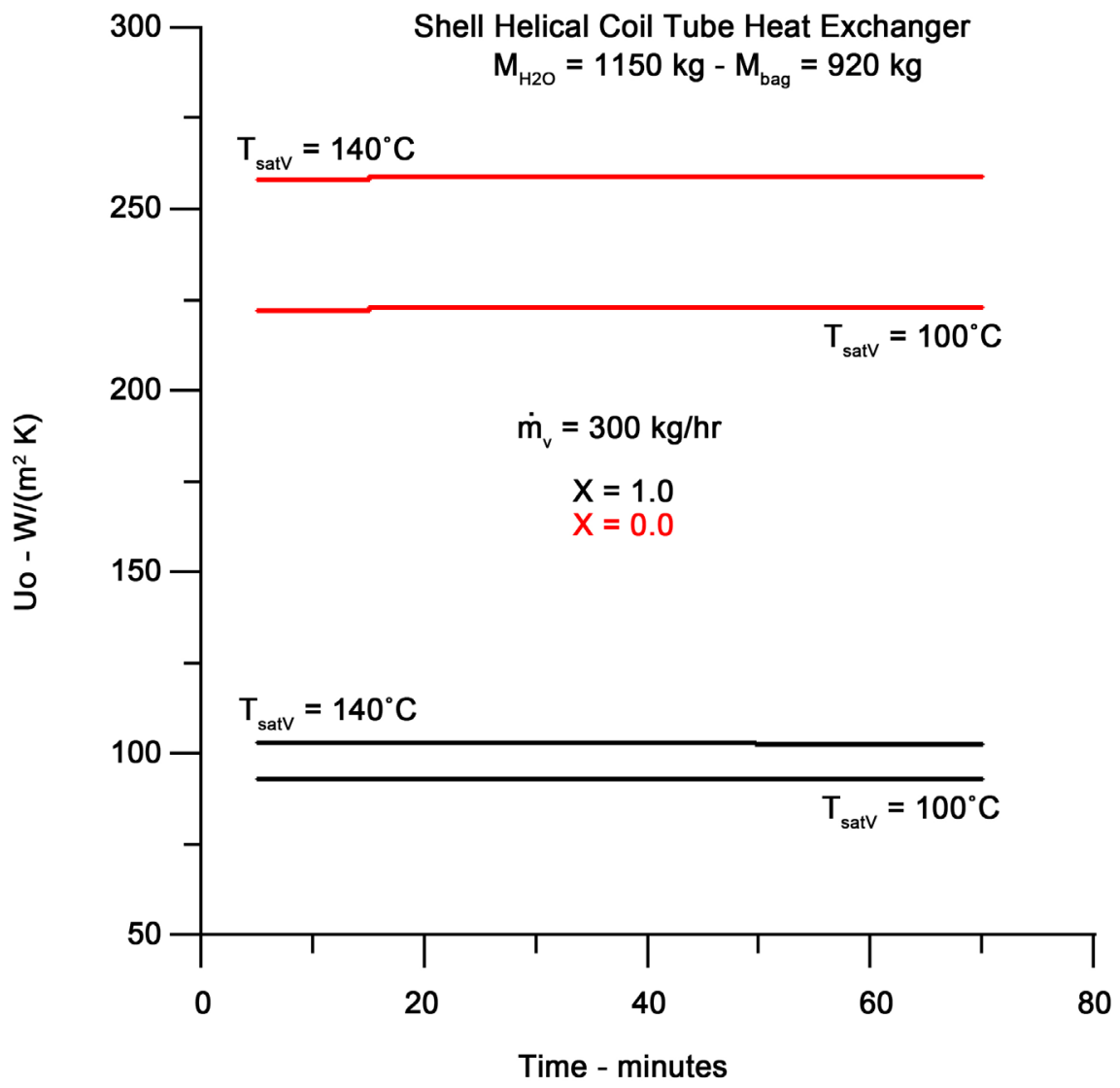

Figure 8. Overall heat transfer coefficient versus time with saturation temperature as a parameter $\left(\dot{m}_{V}=300 \mathrm{~kg} / \mathrm{hr}\right)$. 


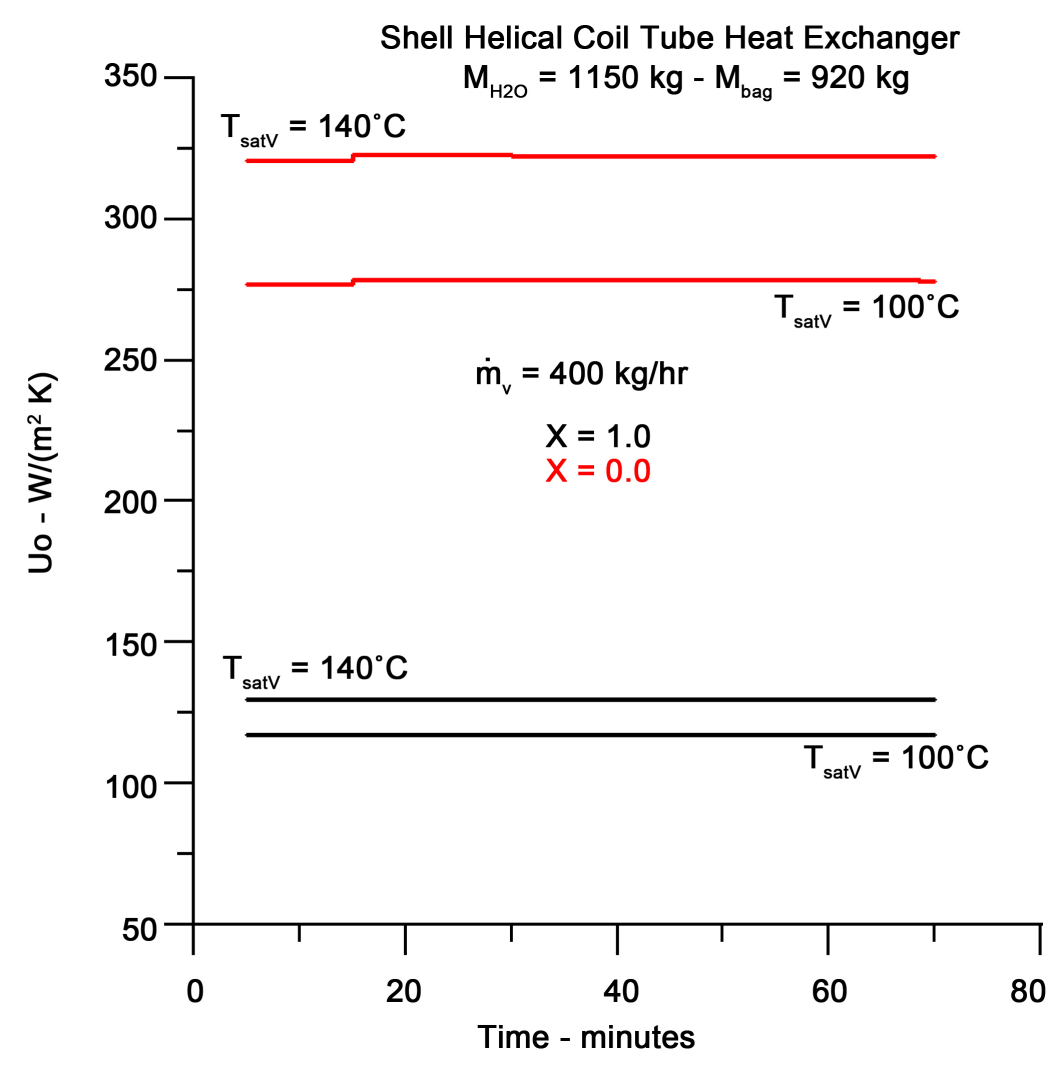

Figure 9. Overall heat transfer coefficient versus time with saturation temperature as a parameter $\left(\dot{m}_{V}=400 \mathrm{~kg} / \mathrm{hr}\right)$.

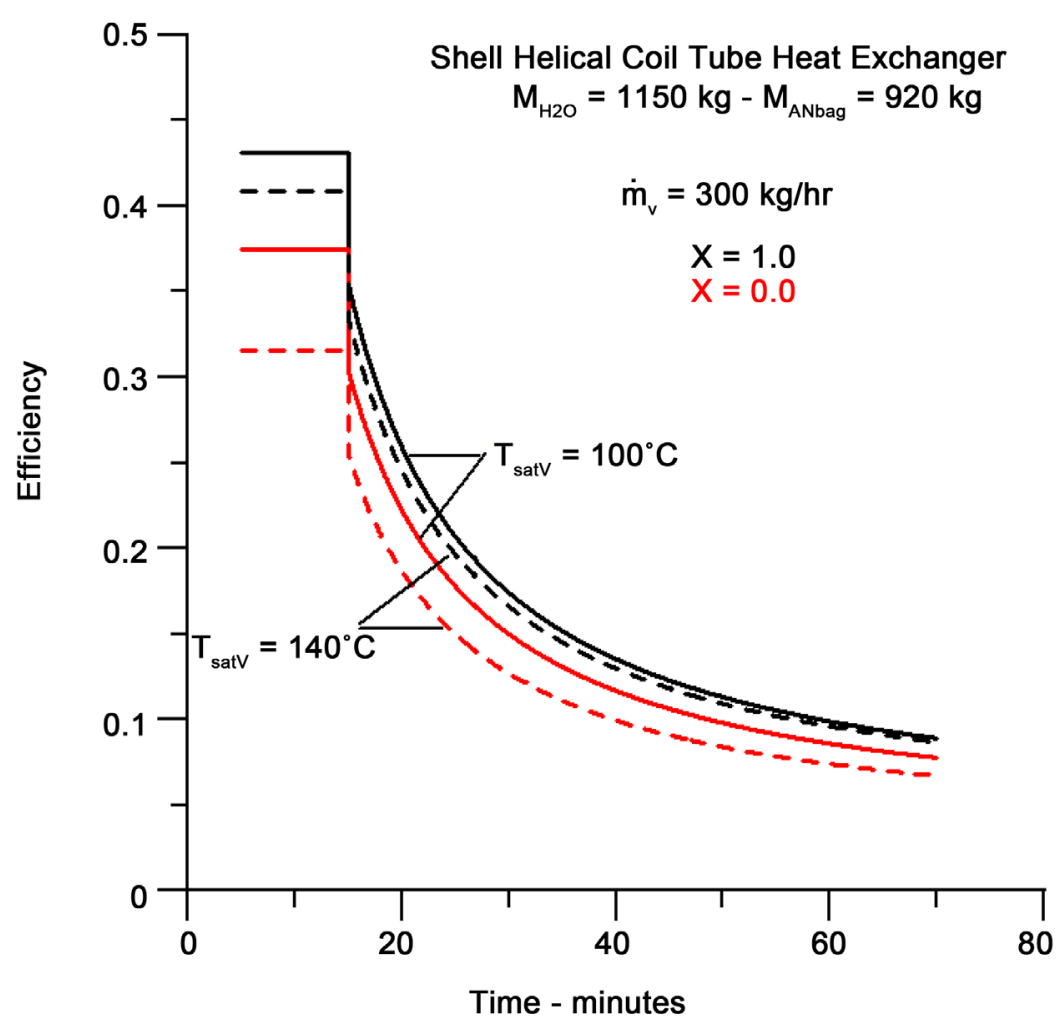

Figure 10. Efficiency versus time with saturation temperature as a parameter. 


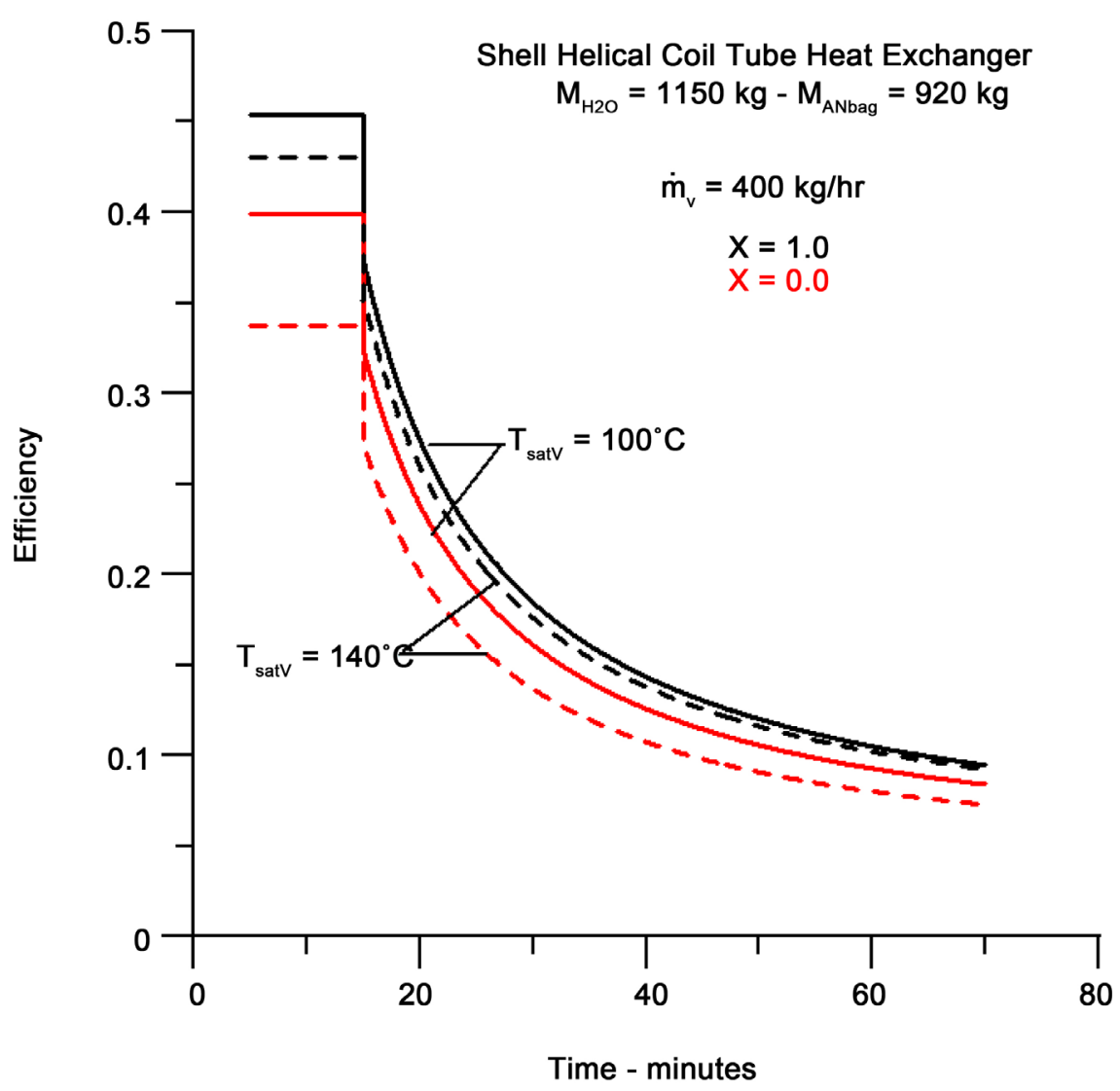

Figure 11. Efficiency versus time with saturation temperature as a parameter.

the efficiency depends on the steam's thermal capacity, or more precisely, on the ratio between the thermal capacities of the ANSOL and the steam.

The thermal effectiveness of the heating and mixing process of $A N S O L$ is shown through Figure 12 and Figure 13. There is no significant variation for effectiveness concerning the analyzed parameters. A relevant fact occurs when the water is being heated about the progressive introduction of ammonium nitrate. It can be seen that the effectiveness is slightly higher for dry saturated steam during heating of the water but decreases, in this case, with the addition of ammonium nitrate. The most relevant parameter in determining effectiveness during the addition of ammonium nitrate is the relationship between the thermal capacities of $A N S O L$ and steam $\left(C_{*}\right)$.

The most essential and definitive results obtained in this work are presented through Figure 14 and Figure 15, where the temperature profiles of ANSOL are shown over the solution's heating time. It is important to note that a batch of $A N S O L$ has a duration of 80 minutes; that is, there are 10 minutes for the solution to be poured out of the tank to start a new batch. During the entire process, the temperature of $A N S O L$ cannot be lower or equal to the crystallization temperature since this can compromise the whole procedure. Also, loss of the heat exchanger may occur.

Figure 14 shows a vapor saturation temperature equal to $120^{\circ} \mathrm{C}$, and its 


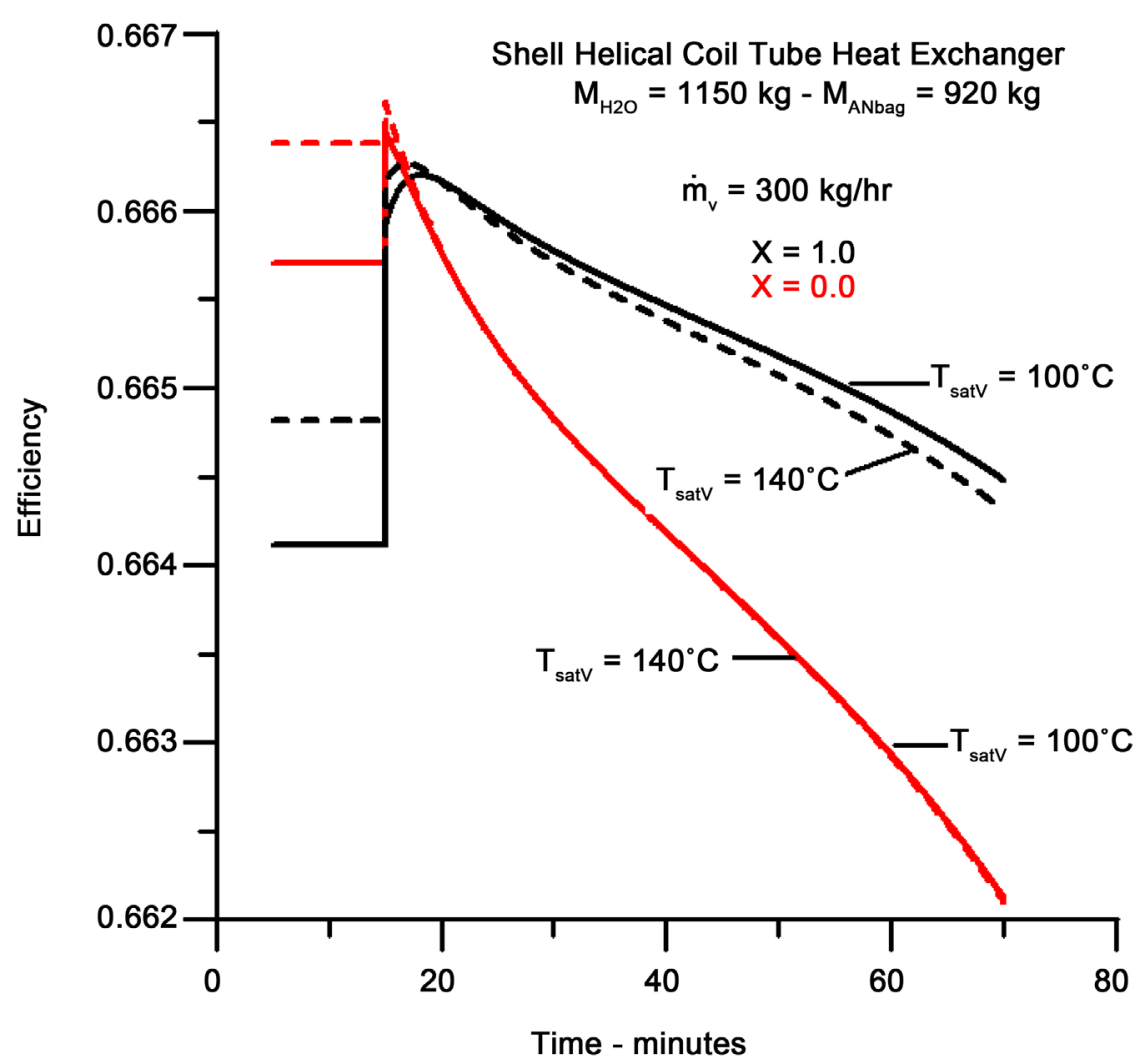

Figure 12. Effectiveness versus time with saturation temperature as a parameter.

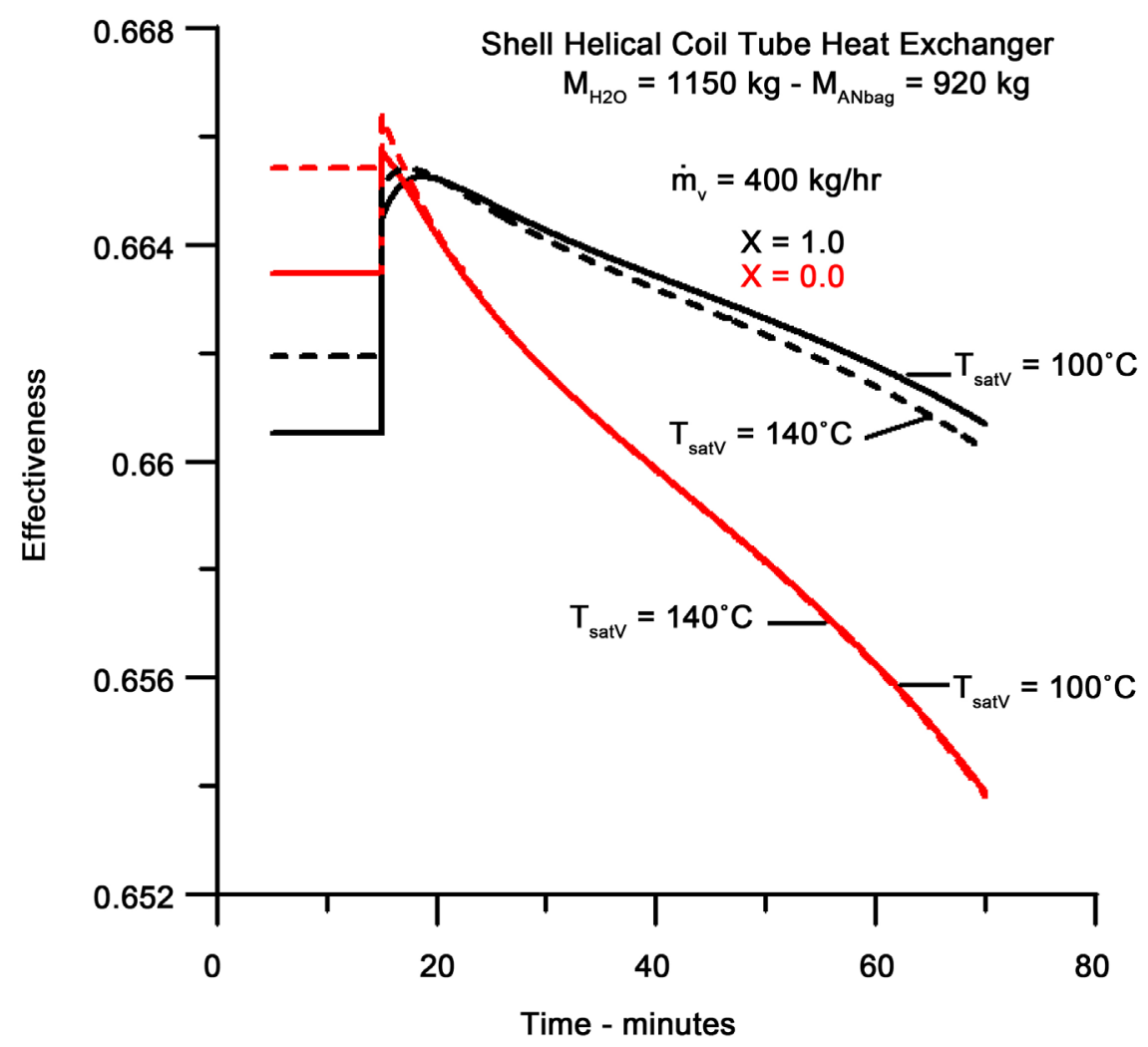

Figure 13. Effectiveness versus time with saturation temperature as a parameter. 


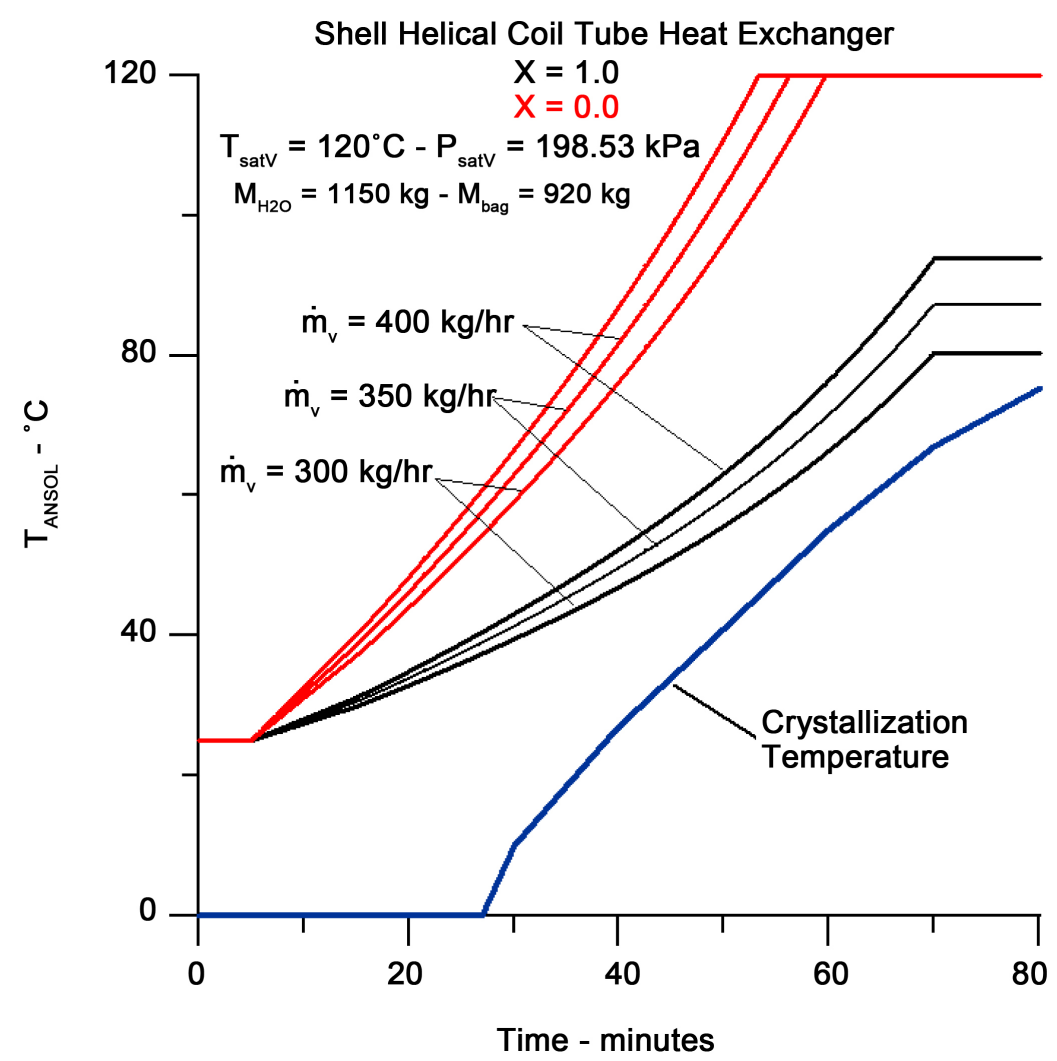

Figure 14. Temperature of the $A N S O L$ versus time.

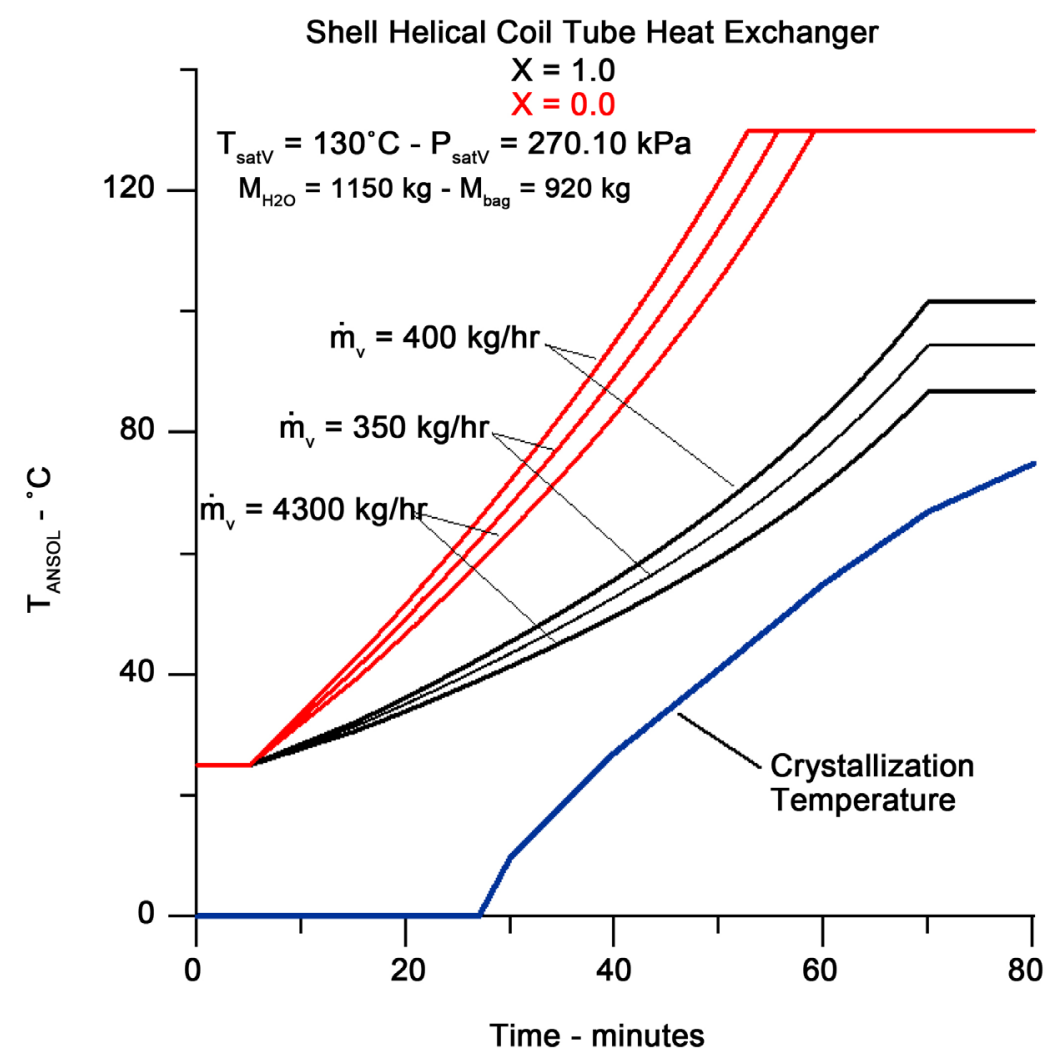

Figure 15. Temperature of the $A N S O L$ versus time. 
corresponding saturation pressure is equal to $198.53 \mathrm{kPa}$. The steam's mass flow rate ranges from $300 \mathrm{~kg} / \mathrm{hr}$ to $400 \mathrm{~kg} / \mathrm{hr}$, and the steam fraction between 0.0 (subcooled liquid) to 1.0 (dry saturated steam). As expected, depending on the values of the global heat transfer coefficient and efficiency already analyzed, the mixture's temperature is higher when the vapor is close to the point of a subcooled liquid $(X=0.0)$, that is, when the heat exchange is higher. A similar situation occurs in Figure 15, where the saturation temperature is equal to $130^{\circ} \mathrm{C}$, and the saturation pressure is equal to $270.10 \mathrm{kPa}$. However, for the saturation temperature equal to $130^{\circ} \mathrm{C}$, the temperature of the $A N S O L$, in time, is significantly higher.

\section{Conclusions}

The results obtained from the analysis demonstrate that the most favorable and safe situation for the heating process of $A N S O L$ is when $400 \mathrm{~kg} / \mathrm{hr}$ of steam is used, and a saturation temperature is equal to $130^{\circ} \mathrm{C}$. In this situation, when the vapor fraction is between 0.0 and 1.0, the temperature of the $A N S O L$ is significantly higher than the crystallization temperature of the mixture, allowing the necessary time to remove it in the event of a failure of the process control system.

Even more relevant is that the flow rate of $400 \mathrm{~kg} / \mathrm{hr}$ is well below the maximum flow rate allowed for the steam and that the saturation pressure is below $361.30 \mathrm{kPa}\left(140^{\circ} \mathrm{C}\right)$. These values demonstrate an economy in the production of steam and that the saturation pressure does not exceed the pressure of the safety valve inserted in the control system.

\section{Acknowledgements}

I thank Eduardo Motta da Cunha, CEO of METTA-Inovação e Tecnologia, and the support team for the incentive and opportunity to solve the case described in this work.

\section{Conflicts of Interest}

The author declares no conflicts of interest regarding the publication of this paper.

\section{References}

[1] Bejan, A. (1987) The Thermodynamic Design of Heat and Mass Transfer Processes and Devices. International Journal of Heat and Fluid Flow, 8, 258-276. https://doi.org/10.1016/0142-727X(87)90062-2

[2] Fakheri, A. (2007) Heat Exchanger Efficiency. Journal of Heat Transfer, 129, 1268-1276. https://doi.org/10.1115/1.2739620

[3] Nogueira, E. (2020) Thermal Performance in Heat Exchangers by the Irreversibility, Effectiveness, and Efficiency Concepts Using Nanofluids. Journal of Engineering Sciences, 7, F1-F7. https://doi.org/10.21272/jes.2020.7(2).f1

[4] Nogueira, É. (2020) Determination of the Best Configuration of a Given Shell and 
Tube Heat Exchanger for Water Cooling Using Nanofluid $(\mathrm{CuO})$ and Concepts of Efficiency, Effectiveness, and Irreversibility. IOSR Journal of Mechanical and Civil Engineering, 17, 24-40.

[5] Nogueira, É. (2020) The Effectiveness Method ( $\varepsilon$-NTU) to Analyze the Thermal Performance of the Flat Tube Multi-Louvered Finned Radiator with Silver Nanoparticles Suspension in Ethylene Glycol. International Journal of Advanced Technology and Engineering Exploration, 7, 102-112.

https://doi.org/10.19101/IJATEE.2020.762040

[6] Alimoradi, A. and Veysi, F. (2017) Optimal and Critical Values of Geometrical Parameters of Shell and Helically Coiled Tube Heat Exchangers. Case Studies in Thermal Engineering, 10, 73-78. https://doi.org/10.1016/j.csite.2017.03.003

[7] Srinivas, T. and Venu Vinod, A. (2015) Heat Transfer Enhancement Using CuO/ Water Nanofluid in a Shell and Helical Coil Heat Exchanger. Procedia Engineering, 127, 1271-1277. https://doi.org/10.1016/j.proeng.2015.11.483

[8] Alimoradi, A. and Veysi, F. (2016) Prediction of Heat Transfer Coefficients of Shell and Coiled Tube Heatexchangers Using Numerical Method and Experimental Validation. International Journal of Thermal Sciences, 107, 196-208.

https://doi.org/10.1016/j.ijthermalsci.2016.04.010

[9] Salimpour, M.R. (2009) Heat Transfer Coefficients of Shell and Coiled Tube Heat Exchangers. Experimental Thermal and Fluid Science, 33, 203-207. https://doi.org/10.1016/j.expthermflusci.2008.07.015

[10] Pawar, Y.Y., Sarode, A.N. and Dahibhate, R.V. (2017) An Experimental and CFD Analysis on Helical Coil Heat Exchanger with Different Geometry. International Journal of Analytical, Experimental and Finite Element Analysis, 4, 21-26.

[11] Smusz, R. (2016) Analytical and Experimental Analysis of Tube Coil Heat Exchanger. Journal of Physics: Conference Series, 745, Article ID: 032083. https://doi.org/10.1088/1742-6596/745/3/032083

[12] Wang, J., Mehri, M., Safarzadeh, M. and Alimoradi, A. (2018) Analysis of Exergy and Energy in the Shell and Helically Coiled Finned Tube Heat Exchangers and Design Optimization. International Journal of Refrigeration, 94, 11-23. https://doi.org/10.1016/j.ijrefrig.2018.07.028

[13] Fule, P.J., Bhanvase, B.A. and Sonawane, S.H. (2017) Experimental Investigation of Heat Transfer Enhancement in Helical Coil Heat Exchangers Using Water-Based CuO Nanofluid. Advanced Powder Technology, 28, 2288-2294. https://doi.org/10.1016/j.apt.2017.06.010

[14] Nilay, A., Gupta, V. and Bagri, S. (2017) Performance Analysis of Helical Coil Heat Exchanger Using Numerical Technique. International Journal of Scientific Research in Science, Engineering and Technology, 3, 152-156.

[15] Salem, M.R., Ali, R.K., Sakr, R.Y. and Elshazly, K.M. (2015) Effect of Al2O3/Water Nanofluid on Heat Transfer and Pressure Drop Characteristics of Shell and Coil Heat Exchanger with Different Coil Curvatures. Journal of Thermal Science and Engineering Applications, 7, Article ID: 041002. https://doi.org/10.1115/1.4030635

[16] Puttewar, A.S. and Andhare, A.M. (2015) Design and Thermal Evaluation of Shell and Helical Coil Heat Exchanger. International Journal of Research in Engineering and Technology, 4, 416-423. http://www.ijret.org https://doi.org/10.15623/ijret.2015.0401064

[17] Abdi, H., Asaadi, S., Azimi Kivi, H. and Mehdi Pesteei, S. (2019) A Comprehensive Numerical Study on Nanofluid Flow and Heat Transfer of Helical, Spiral and Straight Tubes with Different Cross Sections. International Journal of Heat and Technology, 
37, 1031-1042.

[18] Han, Z. (2016) Thermal Stability Studies of Ammonium Nitrate. A Dissertation, DOCTOR OF PHILOSOPHY, Office of Graduate and Professional Studies of Texas A\&M University, Katar.

[19] Coronel, P. and Sandeep, K.P. (2008) Heat Transfer Coefficient in Helical Heat Exchangers under Turbulent Flow Conditions. International Journal of Food Engineering, 4, Article No. 4. https://doi.org/10.2202/1556-3758.1209

[20] Pietranski, J.F. (2012) Over-All Heat Transfer Coefficients in Agitated Vessels. PDHonline Course K102 (4 PDH), PDH Center, Fairfax, 1-32.

https://www.pdhonline.com/ 